\title{
Strategies for the design of additively manufactured nanocomposite scaffolds for hard tissue regeneration
}

\author{
Pierpaolo Fucile ${ }^{1}$, Ilaria Onofrio², Ida Papallo' ${ }^{1}$, Vito Gallicchio², Andrea Rega ${ }^{2}$, Vincenzo D'Antò ${ }^{2}$, \\ Giovanni Improta ${ }^{3}$, Roberto De Santis ${ }^{4}$, Antonio Gloria ${ }^{4}$, Teresa Russo ${ }^{4}$ \\ ${ }^{1}$ Department of Advanced Biomedical Sciences, University of Naples Federico II, 80131 Naples, Italy \\ 2 Department of Neurosciences, Reproductive and Odontostomatological Sciences, University of Naples Federico II, 80131 Naples, Italy \\ 3 Department of Public Health, University of Naples Federico II, 80131 Naples, Italy \\ ${ }^{4}$ Institute of Polymers, Composites and Biomaterials - National Research Council of Italy, 80125 Naples, Italy
}

\section{ABSTRACT}

Additive manufacturing represents a powerful tool for the direct fabrication of lightweight and porous structures with tuneable properties. In this study, a fused deposition modelling/3D fibre deposition technique was considered for designing 3D nanocomposite scaffolds with specific architectures and tailored biological, mechanical, and mass transport properties. 3D poly( $\varepsilon$-caprolactone) $(\mathrm{PCL}) /$ hydroxyapatite $(\mathrm{HA})$ nanocomposite scaffolds were designed for bone tissue engineering. An optimisation design strategy for the additive manufacturing processes based on extrusion/injection methods was at first extended to the development of the PCL/HA scaffolds. Further insight into the effect of the process parameters on the mechanical properties and morphological features of the nanocomposite scaffolds was provided. The nanocomposite structures were analysed at different levels, and the possibility of designing 3D customised scaffolds for mandibular defect regeneration (i.e., symphysis and ramus) was also reported.

Section: RESEARCH PAPER

Keywords: Additive manufacturing; Reverse Engineering; Scaffold Design and Analysis; Design of Experiments; Nanocomposites

Citation: Pierpaolo Fucile, Ilaria Onofrio, Ida Papallo, Vito Gallicchio, Andrea Rega, Vincenzo D'Antò, Giovanni Improta, Roberto De Santis, Antonio Gloria, Teresa Russo, Strategies for the design of additively manufactured nanocomposite scaffolds for hard tissue regeneration, Acta IMEKO, vol. 9, no. 4, article 7, December 2020, identifier: IMEKO-ACTA-09 (2020)-04-07

Section Editor: Leopoldo Angrisani, University of Naples Federico II, Italy

Received October 31, 2019; In final form February 12, 2020; Published December 2020

Copyright: This is an open-access article distributed under the terms of the Creative Commons Attribution 3.0 License, which permits unrestricted use, distribution, and reproduction in any medium, provided the original author and source are credited.

Corresponding authors: Pierpaolo Fucile, e-mail: pierpaolo.fucile@unina.it, Ilaria Onofrio, e-mail: ilaria.onofrio@unina.it

\section{INTRODUCTION}

Bone is capable of healing and remodelling itself except in the case of defects that exceed a critical size [1], [2]. Autografts are generally considered the gold standard for bone reconstruction.

Even though it is reported that there is no risk of device rejection or disease transmission, many complications arise due to poor availability, prolonged hospitalisation, donor-site morbidity and pain, and high risk of infection and haematoma [1]-[3].

For this reason, allografts may be seen as an alternative to autografts but their clinical applications are strongly limited by the risk of pathogenic disease transmission as well as low integration with native tissues [4]-[9].

The use of metallic or ceramic man-made devices may be considered to be an interesting alternative system since these devices can immediately act as a mechanical support, providing the structural stability that is generally needed for the bonehealing process. However, the use of metallic devices may lead to the risk of bone resorption and fracture as a consequence of the low torsion of the great mismatch between the mechanical properties of the implant and the bone.

Alternatively, the brittleness of ceramic devices with high osteointegration and osteoinduction properties clearly limits their use [4], [9]-[16]. Thus, for many years, novel approaches based on the combination of scaffolds with cells and/or biomolecules have been gaining importance as an intriguing strategy with which to overcome the above reported drawbacks [16].

The great challenge should be the design of a suitable biomechanical environment for cell growth and the consequent new tissue formation.

Over previous years, different combinations of scaffold design strategies, materials, biomolecules, and cells have been 
widely investigated in an attempt to promote an effective interaction with the native tissue [17], [18].

In the field of tissue engineering, poly( $\varepsilon$-caprolactone) (PCL), which is an aliphatic polyester, represents one of the most commonly used biodegradable polymers, due to its interesting processability, biodegradation rate, and high thermal and chemical stability [19]-[21].

The development of ceramic materials with a composition similar to the bone mineral phase, such as hydroxyapatite (HA) and tricalcium phosphate, has potentially led to the possibility of improving both the bioactivity and the mechanical properties of the neat polymeric scaffolds [22]-[24].

With regard to bone tissue regeneration, PCL/HA nanocomposite scaffolds with tailored architectures and mechanical and mass transport properties have already been fabricated by additive manufacturing techniques (i.e., fused deposition modelling/3D fibre deposition) that allow the development of customised structures as well as the control of pore geometry and spatial distribution [16].

Nevertheless, it is well known that the process and instrument parameters play an important role in determining the mechanical properties and morphological features of additively manufactured scaffolds. In this context, the influence of the process parameters on these characteristics has previously been studied in the case of 3D additively manufactured PCL scaffolds obtained through a bioextruder [25]. In particular, great efforts were devoted to the study of the effect of the deposition velocity (DV), screw rotation velocity (SRV), slice thickness (ST), and process temperature (PT) to find the best set of parameters for the fabrication of PCL scaffolds with enhanced properties and reproducibility [25]. In the processing of nanocomposite materials, the difficulties are usually greater than those encountered for the neat polymers.

Accordingly, taking into account the previously obtained results for the neat PCL structures [25], in this study, an optimisation design strategy for additive manufacturing processes based on extrusion/injection methods was first employed to develop PCL/HA nanocomposite scaffolds for hard tissue regeneration. The nanocomposite scaffolds were analysed at different levels, and examples of strategies for the development of customised scaffolds were reported.

\section{MATERIALS AND METHODS}

PCL/HA nanocomposite pellets were first developed and then processed through the fused deposition modelling (FDM)/3D fibre deposition technique.

Specifically, PCL $(\mathrm{Mw}=65000$; Sigma-Aldrich, St. Louis, MO) pellets were dissolved in tetrahydrofuran (THF; SigmaAldrich, St. Louis, MO) while stirring at room temperature. HA nanoparticles and, then, ethanol was added to the solution.

A PCL/HA weight ratio (w/w) of 90/10 was considered, and an ultrasonic bath (Branson 1510 MT, Danbury, CT) was employed for the dispersion of the nanoparticles in the PCL/THF solution.

PCL/HA nanocomposite pellets were processed using a bioextruder [25] to fabricate 3D scaffolds (length $L$ of $7.0 \mathrm{~mm}$, width $W$ of $7.0 \mathrm{~mm}$, and height $H_{0}$ of $8.0 \mathrm{~mm}$ ), characterised by a $0 / 90^{\circ}$ lay-down pattern.

A nozzle with an inner diameter of $400 \mu \mathrm{m}$ was used to extrude/inject the material. The nanocomposite fibres/filaments were deposited according to the selected sequence of stacking
Table 1. Manufacturing parameters: slice thickness (ST), deposition velocity (DV), screw rotation velocity (SRV) and process temperature (PT).

\begin{tabular}{cccc}
\hline $\begin{array}{c}\text { ST } \\
(\mu \mathrm{m})\end{array}$ & $\begin{array}{c}\text { DV } \\
(\mathrm{mm} / \mathbf{s})\end{array}$ & $\begin{array}{c}\text { SRV } \\
(\mathbf{r p m})\end{array}$ & $\begin{array}{c}\text { PT } \\
\left({ }^{\circ} \mathbf{C}\right)\end{array}$ \\
\hline 350 & 8 & 20 & 120 \\
380 & 10 & 25 & 130 \\
400 & 12 & 30 & 140 \\
\hline
\end{tabular}

(i.e., lay-down pattern). A fibre spacing (i.e., filament distance [FD]) of $1,000 \mu \mathrm{m}$ was used.

The PCL/HA scaffolds were manufactured using three different values of the ST, DV, SRV, and PT, as shown in Table 1.

With regard to the fabrication of the devices, one parameter was varied iteratively, while maintaining the other three as constant parameters.

The morphology of the scaffolds was investigated by scanning electron microscopy, focusing on the filament diameter, strand distance (centre-to-centre distance), and layer thickness.

The mechanical behaviour of the 3D scaffolds was appropriately analysed.

Compression tests on the 3D scaffolds and nanoindentation analyses on the scaffold fibres were performed to assess the effect of the inclusion of HA nanoparticles on the mechanical behaviour and local surface properties.

In particular, mechanical compression tests were carried out on the fabricated 3D PCL/HA scaffolds. The structures were tested at a cross-head speed of $1 \mathrm{~mm} / \mathrm{min}$ up to a strain of 0.4 $\mathrm{mm} / \mathrm{mm}$, using an INSTRON 5566 testing system.

The 'apparent' stress $\sigma$ and strain $\varepsilon$ were calculated as reported below [16], [25]:

$$
\begin{aligned}
& \sigma=\frac{F}{L \cdot W} \\
& \varepsilon=\frac{\Delta H}{H_{0}}
\end{aligned}
$$

with $F$ representing the force measured by the load cell, whereas $\Delta H$ represents the height variation of the device.

The slope of the initial linear portion of the stress-strain curve was considered to determine the compressive modulus. For each set of parameters (Table 1), five specimens were mechanically tested

Nanoindentation analyses were performed using the Nanotest Platform (Micromaterials, U.K.) in a specific load range $(1-5 \mathrm{mN})$. A diamond pyramid-shaped Berkovich-type indenter tip was employed. The trapezoidal load functions characterised by the specific values for the load hold periods (i.e., $20 \mathrm{~s}$ ) and the loading-unloading rates (i.e., $300 \mu \mathrm{N} / \mathrm{s}$ ) were considered. Using the Oliver and Pharr method, the hardness values were evaluated from the load-depth curves.

The hardness $(H)$ was calculated as follows:

$$
H=\frac{L_{\max }}{A_{\mathrm{c}}}
$$

where $A_{\mathrm{c}}$ and $L_{\max }$ are the projected contact area and the applied peak load, respectively.

The biological performances of the fabricated PCL/HA scaffolds were assessed to analyse the effect of the nanoparticle inclusion.

Briefly, PCL/HA scaffolds were prepared for cell seeding following a reported protocol [16]. PCL and PCL/HA scaffolds 
were seeded with bone marrow-derived human mesenchymal stem cells (hMSCs) using $1 \times 10^{4}$ cells $/$ sample.

The cell viability was evaluated at different time points using the Alamar Blue assay (AbD Serotec Ltd,UK).

The cell adhesion and spreading were analysed at different time points using confocal laser scanning microscopy (CLSM) and rhodamine phalloidin staining.

The Image J software was employed, and a shape factor was introduced to analyse the CLSM images of the cell-scaffold constructs [23].

The shape factor was calculated as follows:

$$
\phi=\frac{4 \pi A}{P^{2}}
$$

with $\mathrm{A}$ and $\mathrm{P}$ representing the area of a cell and the perimeter, respectively.

Considering that circular objects are characterised by the greatest area-to-perimeter ratio, a shape factor of 1 represents a perfect circle. Thin thread-like objects have the lowest shape factor, which approaches zero [23].

An example of the design and production process of customised PCL/HA nanocomposite scaffolds for mandibular defect regeneration (i.e., symphysis and ramus) was also reported, integrating different methodologies and approaches (material synthesis/preparation, reverse engineering, and additive manufacturing), as seen in Figure 1.

Computed tomography (CT) was performed to acquire the image and, consequently, the shape and size of a human mandible.

The obtained point clouds were appropriately processed. Rapidform software and Materialise Magics were used for the reconstruction of the 3D model.

\section{RESULTS}

The roles of reverse engineering [26]-[29], computer-aided design, and finite element analysis [30]-[34] have been frequently stressed in the literature. In addition, over previous years, the advances in methodologies and design strategies have pushed the research towards the development of novel structures for different fields of application [35]-[41].

The functional behaviour of $3 \mathrm{D}$ additive manufactured scaffolds is clearly dependent on the geometric and architectural features, as well as on the pore spatial distribution. Concerning the development of additive manufactured scaffolds, many studies have already demonstrated the possibility of properly tailoring the road width (RW) by varying the instrument and process parameters at a fixed nozzle size [25].

In the current study, a nozzle with an inner diameter of 400 $\mu \mathrm{m}$ was employed to manufacture the PCL/HA nanocomposite scaffolds. In particular, an already considered approach to develop additive manufactured PCL scaffolds [25] was used. The manufacturing parameters were selected to obtain a value of the

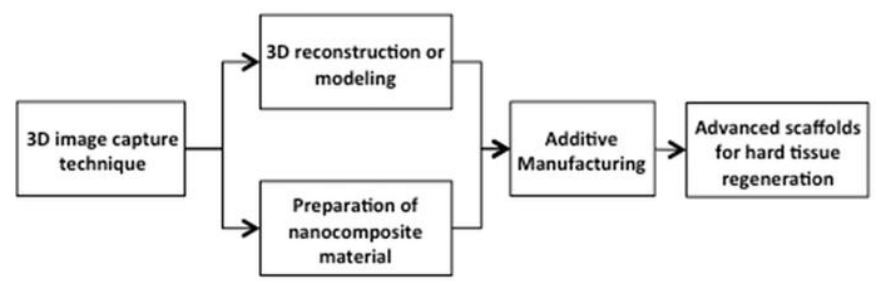

Figure 1. Design and production process of customised PCL/HA scaffolds for hard tissue regeneration.

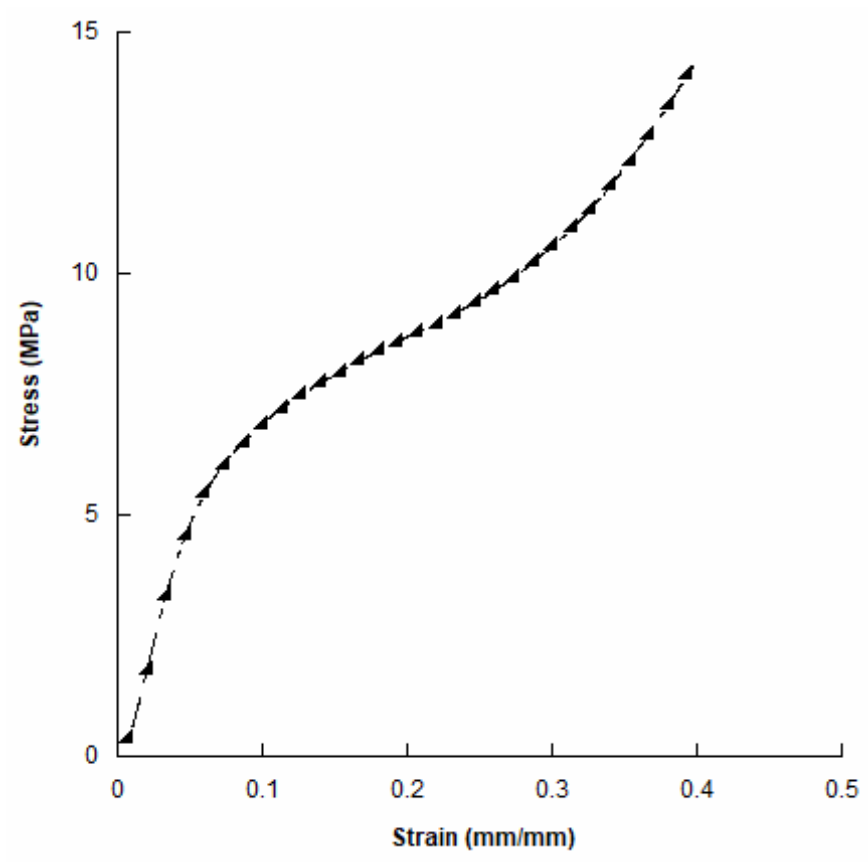

Figure 2. Typical results from compression tests. Stress-strain curves for additive manufactured PCL/HA scaffolds with specific lay-down pattern and geometric features, tested up to a strain of $0.4 \mathrm{~mm} / \mathrm{mm}$.

RW that was equivalent to the inner nozzle diameter $(400 \mu \mathrm{m})$, attempting to reduce the fabrication time and to maintain the highest reproducibility without significant alteration of the structural stability of the devices.

The results obtained from the experimental analyses evidenced the influence of the investigated parameters (PT, SRV, DV, and ST) on the flow behaviour of the material, which clearly resulted in changes in terms of the RW. Such variations provided the $3 \mathrm{D}$ scaffolds with different morphological and mechanical features.

The obtained stress-strain curves (Figure 2) were similar to those found for the 3D additive manufactured scaffolds [16],[25].

The temperature was initially varied $\left(120{ }^{\circ} \mathrm{C}, 130{ }^{\circ} \mathrm{C}\right.$, and $\left.140{ }^{\circ} \mathrm{C}\right)$ at fixed values of the SRV $(30 \mathrm{rpm}), \mathrm{DV}(10 \mathrm{~mm} / \mathrm{s})$, and ST $(400 \mu \mathrm{m})$.

When the temperature increased from $120{ }^{\circ} \mathrm{C}$ to $140{ }^{\circ} \mathrm{C}$, an increase of the RW was evident (Table 2). Conversely, the porosity values decreased (Table 2 ) due to a reduction in the pore height and the pore width (LG and FG, respectively; data not reported).

The findings confirmed the effect of the PT on the morphological features. In particular, a thickening of the filament and a decrease of the scaffold porosity were found with the PT increasing from $120^{\circ} \mathrm{C}$ to $140{ }^{\circ} \mathrm{C}$.

Table 2. RW, porosity, compressive modulus, and maximum stress of 3D $\mathrm{PCL} / \mathrm{HA}$ scaffolds achieved for different PT values $(D V=10 \mathrm{~mm} / \mathrm{s}, S R V$ $=30 \mathrm{rpm}$ and $S T=400 \mu \mathrm{m}$ ). The data are reported as mean value \pm standard deviation.

\begin{tabular}{ccccc}
\hline $\begin{array}{c}\text { PT } \\
\left({ }^{\circ} \mathrm{C}\right)\end{array}$ & $\begin{array}{c}\text { RW } \\
(\mu \mathrm{m})\end{array}$ & $\begin{array}{c}\text { Porosity } \\
(\%)\end{array}$ & $\begin{array}{c}\text { Compressive } \\
\text { Modulus } \\
(\mathrm{MPa})\end{array}$ & $\begin{array}{c}\text { Maximum } \\
\text { Stress } \\
(\mathrm{MPa})\end{array}$ \\
\hline 120 & $449 \pm 5$ & $60.0 \pm 1.2$ & $120.1 \pm 11.4$ & $13.5 \pm 1.4$ \\
130 & $477 \pm 7$ & $55.0 \pm 1.2$ & $124.1 \pm 12.3$ & $14.8 \pm 1.9$ \\
140 & $506 \pm 5$ & $50.9 \pm 1.2$ & $130.2 \pm 14.0$ & $13.3 \pm 2.2$ \\
\hline
\end{tabular}


Table 3. RW, porosity, compressive modulus, and maximum stress of $3 \mathrm{D}$ $\mathrm{PCL} / \mathrm{HA}$ scaffolds achieved for different DV values $\left(P T=120^{\circ} \mathrm{C}, S R V=30 \mathrm{rpm}\right.$ and $S T=400 \mu \mathrm{m})$. The data are reported as mean value \pm standard deviation.

\begin{tabular}{ccccc}
\hline $\begin{array}{c}\text { DV } \\
(\mathrm{mm} / \mathrm{s})\end{array}$ & $\begin{array}{c}\text { RW } \\
(\boldsymbol{\mu \mathrm { m }})\end{array}$ & $\begin{array}{c}\text { Porosity } \\
(\%)\end{array}$ & $\begin{array}{c}\text { Compressive } \\
\text { Modulus } \\
(\mathrm{MPa})\end{array}$ & $\begin{array}{c}\text { Maximum } \\
\text { Stress } \\
(\mathrm{MPa})\end{array}$ \\
\hline 8 & $479 \pm 6$ & $55.6 \pm 1.3$ & $128.1 \pm 12.0$ & $12.5 \pm 1.3$ \\
10 & $449 \pm 5$ & $60.0 \pm 1.2$ & $120.1 \pm 11.4$ & $13.5 \pm 1.4$ \\
12 & $431 \pm 5$ & $64.2 \pm 1.3$ & $91.5 \pm 9.2$ & $9.1 \pm 0.9$ \\
\hline
\end{tabular}

In terms of the mechanical properties, the values of the compressive modulus and the maximum stress are shown in Table 2.

Although differences in terms of the RW and porosity were observed at different PT values, the results suggested that both the compressive modulus and the maximum stress were not greatly affected if the PT was increased above $120^{\circ} \mathrm{C}$.

The influence of the DV on the morphological and mechanical features was investigated by varying the DV $(8,10$, and $12 \mathrm{~mm} / \mathrm{s})$ at fixed values of the SRV $(30 \mathrm{rpm}), \mathrm{ST}(400 \mu \mathrm{m})$ and PT $\left(120^{\circ} \mathrm{C}\right)$.

When the DV increased from 8 to $12 \mathrm{~mm} / \mathrm{s}$, the filament thinning provided an increase in the pore width and the scaffold porosity (Table 3).

Table 3 suggests how the DV may influence both the compressive modulus and the maximum stress of the PCL/HA scaffolds. Specifically, a high value of the DV should negatively affect the mechanical performances of the additive manufactured PCL/HA scaffolds.

Accordingly, in the fast deposition process, the filaments were too stretched, leading to a decrease of the RW and an increase of the porosity. In terms of the compressive modulus and the maximum stress, Table 3 shows that the lowest values were obtained for a DV of $12 \mathrm{~mm} / \mathrm{s}$.

The SRV clearly influences the amount of the extruded/deposited material. To study the effect of the SRV on the scaffold characteristics, the SRV was varied (20, 25, and 30 $\mathrm{rpm})$ at fixed values of the DV $(10 \mathrm{~mm} / \mathrm{s}), \mathrm{ST}(400 \mu \mathrm{m})$ and PT $\left(120^{\circ} \mathrm{C}\right)$.

An increase of the RW was evident with the SRV increasing from 20 to $30 \mathrm{rpm}$ due to the higher amount of extruded material.

However, higher SRV values led to a decrease in the pore width (FG), the pore height (LG), and the porosity (Table 4).

As a consequence of the higher SRV values, the thickening of the filament provided the PCL/HA structures with a lower porosity.

The results reported in Table 4 indicate that the highest values of the compressive modulus and the maximum stress were found for an SRV of $30 \mathrm{rpm}$.

Table 4. RW, porosity, compressive modulus, and maximum stress of $3 \mathrm{D}$ $\mathrm{PCL} / \mathrm{HA}$ scaffolds achieved for different SRV values $\left(P T=120{ }^{\circ} \mathrm{C}, D V=10\right.$ $\mathrm{mm} / \mathrm{s}$ and $S T=400 \mu \mathrm{m}$ ). The data are reported as mean value \pm standard deviation.

\begin{tabular}{ccccc}
\hline $\begin{array}{c}\text { SRV } \\
(\mathrm{rpm})\end{array}$ & $\begin{array}{c}\text { RW } \\
(\boldsymbol{\mu m})\end{array}$ & $\begin{array}{c}\text { Porosity } \\
(\%)\end{array}$ & $\begin{array}{c}\text { Compressive } \\
\text { Modulus } \\
(\mathrm{MPa})\end{array}$ & $\begin{array}{c}\text { Maximum } \\
\text { Stress } \\
(\mathrm{MPa})\end{array}$ \\
\hline 20 & $381 \pm 6$ & $71.3 \pm 1.7$ & $65.6 \pm 6.8$ & $9.2 \pm 0.8$ \\
25 & $430 \pm 5$ & $63.7 \pm 1.4$ & $81.3 \pm 8.9$ & $9.7 \pm 0.8$ \\
30 & $449 \pm 5$ & $60.0 \pm 1.2$ & $120.1 \pm 11.4$ & $13.5 \pm 1.4$ \\
\hline
\end{tabular}

Table 5. RW, porosity, compressive modulus, and maximum stress of $3 \mathrm{D}$ $\mathrm{PCL} / \mathrm{HA}$ scaffolds achieved for different $\mathrm{ST}$ values $\left(P T=120^{\circ} \mathrm{C}, D V=10 \mathrm{~mm} / \mathrm{s}\right.$ and $S R V=30 \mathrm{rpm})$. The data are reported as mean value \pm standard deviation.

\begin{tabular}{ccccc}
\hline $\begin{array}{c}\text { ST } \\
(\boldsymbol{\mu m})\end{array}$ & $\begin{array}{c}\text { RW } \\
(\boldsymbol{\mu m})\end{array}$ & $\begin{array}{c}\text { Porosity } \\
(\%)\end{array}$ & $\begin{array}{c}\text { Compressive } \\
\text { Modulus } \\
(\mathrm{MPa})\end{array}$ & $\begin{array}{c}\text { Maximum } \\
\text { Stress } \\
(\mathrm{MPa})\end{array}$ \\
\hline 350 & $489 \pm 6$ & $46.8 \pm 1.3$ & $137.1 \pm 13.8$ & $15.2 \pm 1.4$ \\
380 & $469 \pm 6$ & $53.3 \pm 1.2$ & $130.3 \pm 13.1$ & $14.4 \pm 1.3$ \\
400 & $449 \pm 5$ & $60.0 \pm 1.2$ & $120.1 \pm 11.4$ & $13.5 \pm 1.4$ \\
\hline
\end{tabular}

The ST also plays an important role in determining the filament diameter, pore width, pore height, and porosity, thus providing the possibility of tailoring the scaffold characteristics [25].

Intuitively, a decrease of the ST values generates a compression of the filaments in the adjacent layers and, hence, a change in the geometry of the filaments, which become more elliptical. This effect causes an increase of the filament diameter, together with a reduction of the pore width and porosity.

As the ST decreased from 400 to $350 \mu \mathrm{m}$, a decrease of the pore height was obviously obtained, as well as an increment of the filament diameter and, consequently, a reduction of the pore width and porosity (Table 5).

For this reason, the ST would influence the mechanical properties. However, Table 5 reports the values of the compressive modulus and the maximum stress.

The current analysis was focused on the assessment of the optimal set of process/instrument parameters for the fabrication of PCL/HA nanocomposite scaffolds with minimal fabrication time avoiding to compromise the structural integrity and reproducibility features.

Accordingly, all the parameters were selected to find a value of the RW that was equivalent to the inner diameter of the employed nozzle $(400 \mu \mathrm{m})$.

As frequently stressed in the literature [25], additive manufacturing techniques based on extrusion/injection methods (i.e., fused deposition modelling/3D fibre deposition) enable the possibility of controlling the architectures, pore size, and distribution, consequently leading to the development of $3 \mathrm{D}$ scaffolds with tailored mechanical and mass transport properties.

In this context, the present study analysed the effects of the PT, DV, SRV, and ST on the RW, which influence the pore size and porosity, as well as the compressive modulus and the maximum.

The interaction of different pairs of parameters on the investigated features of the PCL/HA scaffolds (i.e., RW, compressive modulus, and maximum stress) is reported in Figure 3-Figure 5.

For example, Figure 3 illustrates the interaction plot for the RW, reporting the combined effects (PT and DV, PT and SRV, $\mathrm{PT}$ and ST) on the RW.

Similarly, the interaction plots for the maximum stress and the compressive modulus are shown in Figure 4 and 5, respectively.

Table 6 summarises the optimised set of parameters for the manufacturing of 3D PCL/HA $(90 / 10 \mathrm{w} / \mathrm{w})$ scaffolds characterised by a pre-defined value of the RW, pore size, and porosity, without compromising the structural and mechanical characteristics.

The results from the nanoindentation tests on the PCL fibres provided values of hardness ranging from $0.43 \pm 0.03 \mathrm{GPa}$ to $0.26 \pm 0.02 \mathrm{GPa}$ in the investigated load range (Figure 6). 


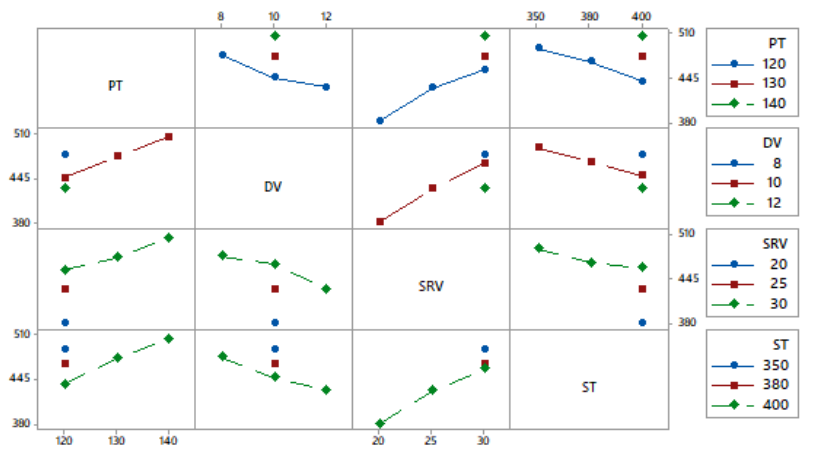

Figure 3. Interaction plot for RW $(\mu \mathrm{m})$.

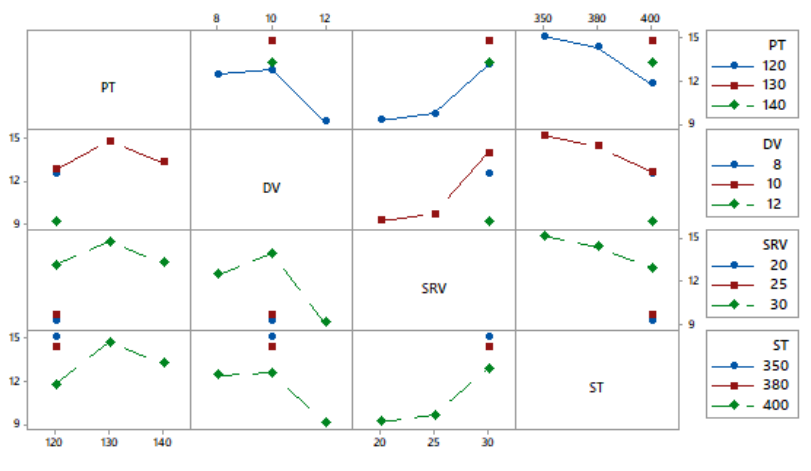

Figure 4. Interaction plot for maximum stress (MPa).

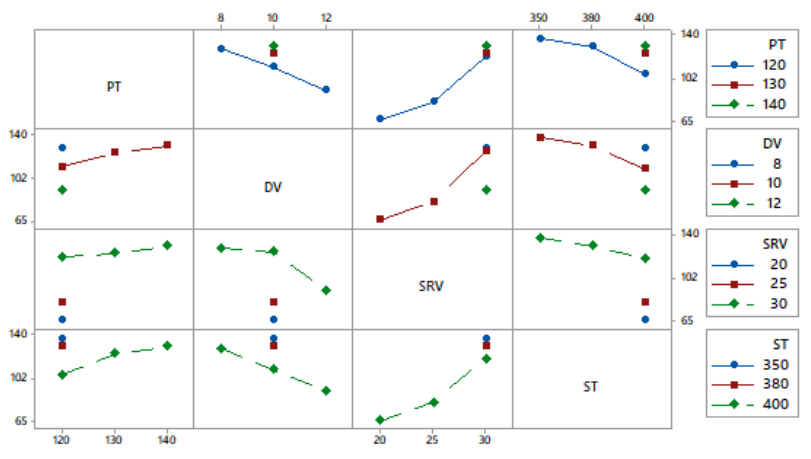

Figure 5. Interaction plot for the compressive modulus (MPa).

The inclusion of HA nanoparticles led to an increase in the compressive modulus and the fibre hardness.

In vitro biological tests were performed to evaluate the influence of the inorganic nanoparticles on the behaviour of the hMSCs.

Typical results obtained from the Alamar Blue assay are reported in Figure 7.

With regard to the biological performances, the Alamar Blue assay was employed to assess the cell viability and proliferation. This method is based on a redox reaction that occurs in the cell mitochondria.

Table 6. Optimised set of parameters for the fabrication of PCL/HA (90/10 $\mathrm{w} / \mathrm{w})$ scaffolds through a bioextruder system.

\begin{tabular}{cccc}
\hline $\begin{array}{c}\text { PT } \\
\left({ }^{\circ} \mathrm{C}\right)\end{array}$ & $\begin{array}{c}\text { DV } \\
(\mathrm{mm} / \mathrm{s})\end{array}$ & $\begin{array}{c}\text { SRV } \\
(\mathbf{r p m})\end{array}$ & $\begin{array}{c}\text { ST } \\
(\boldsymbol{\mu} \mathrm{m})\end{array}$ \\
\hline 120 & 10 & 30 & 400 \\
\hline
\end{tabular}

The percentage of Alamar Blue reduction is related to the number of viable cells. Specifically, a significant increase of Alamar Blue reduction was found over time, indicating that the hMSCs could survive and proliferate throughout the scaffolds.

Although no differences were observed between the PCL/HA scaffolds and the PCL structures at Day 1, the inclusion of HA significantly enhanced the cell viability/proliferation at Day 3 and Day 7 (Figure 7).

The CLSM images and cell-shape factor further allowed investigation of the cell adhesion and spreading.

The shape factor significantly decreased over time for both types of cell-laden constructs, and the typical values are reported in Figure 8.

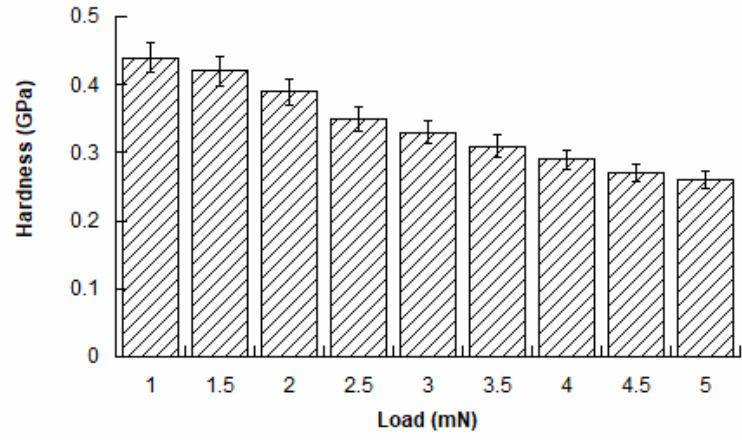

Figure 6. Results obtained from nanoindentation tests on the PCL fibres. Hardness as a function of the applied load. The data are reported as the mean value, and the error bar represents the standard deviation.

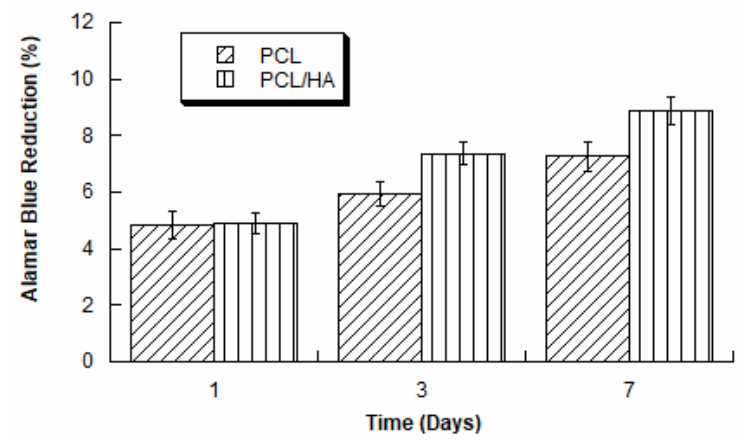

Figure 7. Percentage of Alamar Blue Reduction for the $\mathrm{PCL}$ and the $\mathrm{PCL} / \mathrm{HA}$ scaffolds at Day 1, Day 3, and Day 7. The data are reported as the mean value, and the error bar represents the standard deviation.

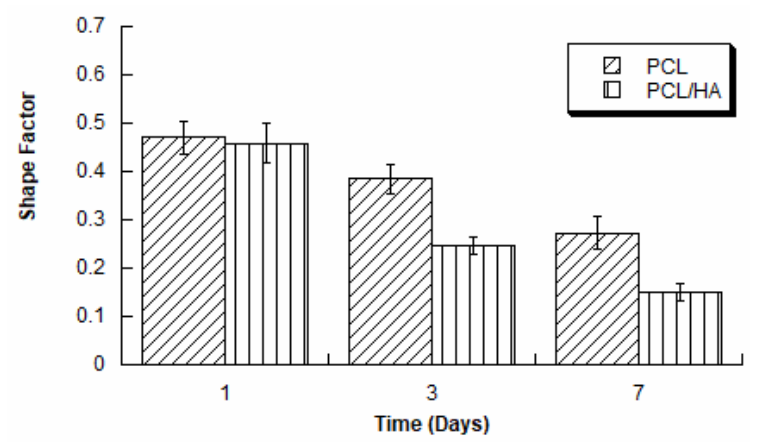

Figure 8. Values of the shape factor obtained from the CLSM images of the hMSCs on the PCL and PCL/HA nanocomposite scaffolds. The data are reported as the mean value, and the error bar represents the standard deviation. 

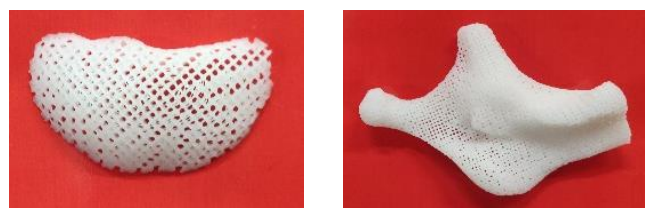

Figure 9. Customised PCL/HA scaffolds for mandibular defect regeneration (i.e., symphysis - left, ramus - right).

In comparison to the neat PCL scaffolds, at Day 3 and Day 7, a lower shape factor was achieved for the PCL/HA nanocomposite structures, even though at Day 1 similar values were found for the two types of cell-laden constructs.

It is also worth noting that a reduction of the shape factor should suggest better cell adhesion and spreading, since the lower the shape factor, the more elongated the cell [16]. These results confirmed the effect of the HA inclusion in enhancing cell adhesion.

Furthermore, considering the obtained results, the reverse engineering approach was also employed to develop customised and functional nanocomposite scaffolds for mandibular defect regeneration (i.e., symphysis and ramus; Figure 9).

\section{CONCLUSIONS}

A systematic study on the design of PCL/HA scaffolds for hard tissue regeneration was reported in the current research.

In particular, 3D PCL/HA scaffolds were designed and analysed according to a strategy already reported for additive manufacturing of PCL scaffolds, involving techniques based on extrusion/injection methods. The procedure was extended to PCL/HA, considering that the difficulties in processing nanocomposite materials are usually greater than those found for the neat polymers.

The neat PCL scaffolds represented the starting point in the design process, and the results from different analyses were briefly summarised.

The reported design strategy also aimed to stress the potential of tailoring the performances of 3D additive manufactured scaffolds through an appropriate material-design combination.

Similar stress-strain curves were achieved for the polymeric and the nanocomposite scaffolds, even if differences were obtained in terms of the mechanical properties.

The inclusion of HA nanoparticles would enhance both the biological and mechanical performances of the PCL scaffolds.

Furthermore, the obtained findings demonstrated that the DV and the SRV were the parameters with the highest impact on the investigated features (i.e., the RW, the compressive modulus, and the maximum stress).

Benefiting from all the results, as well as from the reverse engineering approach, the feasibility of designing customised scaffolds for mandibular defect regeneration (i.e., ramus and symphysis) was also reported.

\section{REFERENCES}

[1] J. Lee, M. M. Farag, E. K. Park, J. Lim, H. Yun, A simultaneous process of 3D magnesium phosphate scaffold fabrication and bioactive substance loading for hard tissue regeneration, Material Science and Engineering: C 36(1) (2014), pp. 252-260. DOI: https://doi.org/10.1016/i.msec.2013.12.007

[2] P. Lichte, H. C. Pape, T. Pufe, P. Kobbe, H. Fischer, Scaffolds for bone healing: concepts, materials and evidence, Injury 42(6) (2011), pp. 569-573.

DOI: https://doi.org/10.1016/j.injury.2011.03.033
[3] A. Oryan, S. Alidati, A. Moshiri, N. Maffulli, Bone regenerative medicine: classic options, novel strategies, and future directions. Journal of Orthopaedic Surgery and Research 9(1) (2014), pp. 1845. DOI: https://doi.org/10.1186/1749-799X-9-18

[4] M. J. Yaszemski, J. B. Oldham, L. Lu, B. L. Currier, Clinical Needs for Bone Tissue Engineering Technology, in: Bone Engineering. J. E. Davies (editor). University of Toronto, Toronto, 2000, ISBN:096869800x; pp. 541-547.

[5] R. Spitzer, C. Perka, K. Lindenhayn, H. Zippel, Matrix engineering for osteogenic differentiation of rabbit periosteal cells using a-tricalcium phosphate particles in a threedimensional fibrin culture, J Biomed Mater Res A 59(4) (2002), pp. 690-696. DOI: https://doi.org/10.1002/ibm.1277

[6] R. Fontanella, D. Accardo, R. Schiano Lo Moriello, L. Angrisani, D. De Simone, An innovative strategy for accurate thermal compensation of gyro bias in inertial units by exploiting a novel Augmented Kalman Filter, Sensors 8(5) (2018) 1457.

DOI: https://doi.org/10.3390/s18051457

[7] G. C. Simon, C. A. Khatri, S. A. Wight, F. W. Wang, Preliminary report on the biocompatibility of a moldable, resorbable, composite bone graft consisting of calcium phosphate cement and poly(lactide-co-glycolide) microspheres, J Orthop Res 20(3) (2002), pp. 473-482.

DOI: https://doi.org/10.1016/S0736-0266(01)00140-1

[8] H. Petite, V. Viateau, W. Bensaid, A. Meunier, C. de Pollak, M. Bourguignon, K. Oudina, L. Sedel, G. Guillemin, Tissueengineered bone regeneration, Nat Biotechnol 18(9) (2000); ISBN:096869800x; pp. 959-963. DOI: https://doi.org/10.1038/79449

[9] D. F. Williams, Perspectives on the contributions of biomaterials and tissue engineering to bone repair, reconstruction and regeneration, in: Bone engineering. J. E. Davies (editor). University of Toronto, Toronto, 2000, ISBN, pp. 577-584.

[10] I. Seto, I. Asahina, M. Oda, S. Enomoto, Reconstruction of the primate mandible with a combination graft of recombinant human bone morphogenetic protein-2 and bone marrow, J Oral Maxillofac Surg 59(1) (2001), pp. 53-61.

DOI: https://doi.org/10.1053/joms.2001.19286

[11] C. G. Finkemeier, Bone-grafting and bone-graft substitutes, J Bone Joint Surg 84(3) (2002), pp. 454-464. DOI: https://doi.org/10.2106/00004623-200203000-00020

[12] L. Angrisani, F. Bonavolontà, A. Liccardo R. Schiano Lo Moriello, L. Ferrigno, M. Laracca, G. Miele, Multichannel simultaneous data acquisition through a compressive sampling-based approach, Measurement 52 (2014), pp. 156-172. DOI: https://doi.org/10.1016/j.measurement.2014.02.031

[13] F. Bonavolontà, A. Tedesco, , R. Schiano Lo Moriello, A. Tufano, Enabling wireless technologies for industry 4.0: State of the art., Proc. of IEEE International Workshop on Measurement and Networking, M \& N 2017, Naples, Italy, 27-29 September 2017, pp. 1-5. DOI: https://doi.org/10.1109/IWMN.2017.8078381

[14] S. N. Khan, E. Tomin, J. M. Lane, Clinical applications of bone graft substitutes, Orthop Clin North Am 31(3) (2000), pp. 389398. DOI: https://doi.org/10.1016/s0030-5898(05)70158-9

[15] F. P. W. Melchels, M. A. N. Domingos, T. J. Klein, J. Malda, P. J. Bartolo, D. W. Hutmacher, Additive manufacturing of tissues and organs, Prog Polym Sci 37(8) (2012), pp. 1079-1104. DOI: https://doi.org/10.1016/j.progpolymsci.2011.11.007

[16] M. Domingos, A. Gloria, J. Coelho, P. Bartolo, J. Ciurana, Threedimensional printed bone scaffolds: The role of nano/microhydroxyapatite particles on the adhesion and differentiation of human mesenchymal stem cells, Proc. Inst. Mech. Eng. H. 231(6) (2017), pp. 555-564.

DOI: https://doi.org/10.1177/0954411916680236

[17] S. H. Lee, H. Shin, Matrices and scaffolds for delivery of bioactive molecules in bone and cartilage tissue engineering, Adv Drug 
Deliv Rev 59 (2007), pp. 339-359.

DOI: https://doi.org/10.1016/i.addr.2007.03.016

[18] E. J. Anderson, M. L. K. Tate, Design of tissue engineering scaffolds as delivery devices for mechanical and mechanically modulated signals, Tissue Eng 13(10) (2007), pp. 2525-2538. DOI: https://doi.org/10.1089/ten.2006.0443

[19] M. A. Woodruff, D. W. Hutmacher, The return of a forgotten polymer - polycaprolactone in the 21st century, Prog Polym Sci 35(10) (2010), pp. 1217-1256.

DOI: https://doi.org/10.1016/i.progpolymsci.2010.04.002

[20] J. Rich, T. Jaakkola, T. Tirri, T. Närhi, A. Yli-Urpo, J. Seppälä, In vitro evaluation of poly( $\varepsilon$-caprolactone-co-DL-lactide)/bioactive glass composites, Biomaterials 23(10) (2002), pp. 2143-2150. DOI: https://doi.org/10.1016/S0142-9612(01)00345-3

[21] H. W. Kim, J. C. Knowles, H. E. Kim, Hydroxyapatite/poly( $\varepsilon-$ caprolactone) composite coatings on hydroxyapatite porous bone scaffold for drug delivery, Biomaterials 25 (2004), pp. 1279-1287. DOI: https://doi.org/10.1016/i.biomaterials.2003.07.003

[22] S. M. S. Bidic, J. W. Calvert, K. Marra, P. Kumta, P. Campbell, R. Mitchell, W. Wigginton, J. O. Hollinger, L. Weiss, M. P. Mooney, Rabbit calvarial wound healing by means of seeded caprotite ${ }^{\circledR}$ scaffolds, J Dent Res 82(2) (2003), pp. 131-135. DOI: https://doi.org/10.1177/154405910308200211

[23] M. Fini, G. Giavaresi, N. N. Aldini, P. Torricelli, R. Botter, D. Beruto, R. Giardino, A bone substitute composed of polymethylmethacrylate and $\alpha$-tricalcium phosphate: results in terms of osteoblast function and bone tissue formation, Biomaterials 23(23) (2002), pp. 4523-4531. DOI: https://doi.org/10.1016/s0142-9612(02)00196-5

[24] S. J. Peter, L. Lu, D. J. Kim, A. G. Mikos, Marrow stromal osteoblast function on a poly(propylene fumarate) $/ \beta$-tricalcium phosphate biodegradable orthopaedic composite, Biomaterials 21(12) (2000), pp. 1207-1213. DOI: https://doi.org/10.1016/s0142-9612(99)00254-9

[25] M. Domingos, F. Chiellini, A. Gloria, L. Ambrosio, P. Bartolo, E. Chiellini, Effect of process parameters on the morphological and mechanical properties of $3 \mathrm{D}$ bioextruded poly $(\varepsilon$ caprolactone) scaffolds, Rapid Prototyping Journal 18 (2012), pp. 56-67.

DOI: https://doi.org/10.1108/13552541211193502

[26] M. Martorelli, P. Ausiello, R. Morrone, A new method to assess the accuracy of a Cone Beam Computed Tomography scanner by using a non-contact reverse engineering technique, Journal of Dentistry 42(4) (2014), pp. 460-465. DOI: https://doi.org/10.1016/i.jdent.2013.12.018

[27] M. Calì, D. Speranza, M. Martorelli, Dynamic Spinnaker Performance through digital photogrammetry, numerical analysis and experimental tests, Advances on Mechanics, Design Engineering and Manufacturing. Springer, Cham (2017), pp. 585595. DOI: https://doi.org/10.1007/978-3-319-45781-9 59

[28] V. Pagliarulo, F. Farroni, P. Ferraro, A. Lanzotti, M. Martorelli, P. Memmolo, D. Speranza, F. Timpone, Combining ESPI with laser scanning for 3D characterization of racing tyres sections, Optics and Lasers in Engineering 104 (2018), pp. 71-77. DOI: https://doi.org/10.1016/i.optlaseng.2017.07.004

[29] M. Martorelli, C. Pensa, D. Speranza, Digital photogrammetry for documentation of maritime heritage, Journal of Maritime Archaeology 9(1) (2014), pp. 81-93. DOI: https://doi.org/10.1007/s11457-014-9124-x

[30] P. Ausiello, S. Ciaramella, M. Martorelli, A. Lanzotti, A. Gloria, D. C. Watts, CAD-FE modeling and analysis of class II restorations incorporating resin-composite, glass ionomer and glass ceramic materials, Dental Materials 33(12) (2017), pp. 14561465.

DOI: https://doi.org/10.1016/i.dental.2017.10.010
[31] P. Ausiello, S. Ciaramella, M. Martorelli, A. Lanzotti, F. Zarone, D. C. Watts, A. Gloria, Mechanical behavior of endodontically restored canine teeth: Effects of ferrule, post material and shape, Dental Materials 33(12) (2017), pp. 1466-1472. DOI: https://doi.org/10.1016/i.dental.2017.10.009

[32] F. Caputo, A. De Luca, A. Greco, S. Maietta, M. Bellucci, FE simulation of a SHM system for a large radio-telescope, International Review on Modelling and Simulations 11(1) (2018), pp. 5-14.

DOI: https://doi.org/10.15866/iremos.v11i1.14784

[33] L. Angrisani, F. Bonavolonta, R. Schiano Lo Moriello, A. Andreone, R. Casini, G. Papari, D. Accardo, First steps towards an innovative compressive sampling based-THz imaging system for early crack detection on aereospace plates, Proc. of IEEE Metrology for Aerospace (MetroAeroSpace), Benevento, Italy, 29-30 May 2014, pp. 488-493.

DOI: https://doi.org/10.1109/MetroAeroSpace.2014.6865974

[34] A. Gloria, S. Maietta, M. Martorelli, A. Lanzotti, D. C. Watts, P. Ausiello, FE analysis of conceptual hybrid composite endodontic post designs in anterior teeth, Dental Materials 34(7) (2018), pp. 1063-1071

DOI: https://doi.org/10.1016/i.dental.2018.04.004

[35] L. Angrisani, F. Bonavolontà, A. Liccardo, R. Schiano Lo Moriello, On the use of LORA technology for logic selectivity in MV distribution networks, Energies, 11(11) (2018), 3079, 34 pages. DOI: https://doi.org/10.3390/en11113079

[36] L. Angrisani, F. Bonavolontà,

A. Liccardo, R. Schiano Lo Moriello, F. Serino, Smart power meters in augmented reality environment for electricity consumption awareness, Energies, 11 (9) (2018), 2303, 17 pages. DOI: https://doi.org/10.3390/en11092303

[37] F. Bonavolontà, M. D'Arco, G. Ianniello, A. Liccardo, R. Schiano Lo Moriello, L. Ferrigno, M. LAracca, G. Miele, On the suitability of compressive sampling for the measurement of electrical power quality, Proc. of Instrumentation and Measurement Technology Conference (I2MTC), Minneapolis, USA, 6-9 May 2013, pp. 126131.

DOI: https://doi.org/10.1109/I2MTC.2013.6555395

[38] A. Baccigalupi, A. Liccardo, The Huang Hilbert Transform for evaluating the instantaneous frequency evolution of transient signals in non-linear systems, Measurement 86 (2016), pp. 1-13. DOI: https://doi.org/10.1016/i.measurement.2016.02.018

[39] C. Landi, A. Liccardo, N. Polese, Remote laboratory activities to support experimental session for undergraduate measurements courses, Proc. of IEEE Instrumentation and Measurement Technology Conference (IMTC), Sorrento, Italy, 24-27 April 2006, pp. 851-856 DOI: https://doi.org/10.1109/IMTC.2006.328232

[40] P. Bifulco, G. D. Gargiulo, G. D'Angelo, A. Liccardo, M. F. Romano, F. Clemente, M. Cesarelli, Monitoring of respiration, seismocardiogram and heart sounds by a PVDF piezo film sensor, Proc. of XX IMEKO TC4 International Symposium, Benevento, Italy, 15-17 Sept. 2014, pp.786-789. Online [accessed 05 December 2020] https://www.imeko.org/publications/tc4-2014/IMEKO-TC42014-285.pdf

[41] M. Giordano, P. Ausiello, M. Martorelli, R. Sorrentino, Reliability of computer designed surgical guides in six implant rehabilitations with two years follow-up, Dental Materials 28(9) (2012), pp. e168e177.

DOI: https://doi.org/10.1016/i.dental.2012.06.005 